\title{
Intimacy Negotiated: The Management of Relationships and The Construction of Personal Communities in the Lives of Bisexual Women and Men
}

Toft, A \& Yip, AK-T

Author post-print (accepted) deposited by Coventry University's Repository

Original citation \& hyperlink:

Toft, A \& Yip, AK-T 2017, 'Intimacy Negotiated: The Management of Relationships and The Construction of Personal Communities in the Lives of Bisexual Women and Men' Sexualities, vol 21, no. 1-2, pp. 233-250

http://dx.doi.org/10.1177/1363460716679793

DOI $\quad 10.1177 / 1363460716679793$

ISSN $1363-4607$

ESSN $1461-7382$

Publisher: Sage

Copyright $\odot$ and Moral Rights are retained by the author(s) and/ or other copyright owners. A copy can be downloaded for personal non-commercial research or study, without prior permission or charge. This item cannot be reproduced or quoted extensively from without first obtaining permission in writing from the copyright holder(s). The content must not be changed in any way or sold commercially in any format or medium without the formal permission of the copyright holders.

This document is the author's post-print version, incorporating any revisions agreed during the peer-review process. Some differences between the published version and this version may remain and you are advised to consult the published version if you wish to cite from it. 


\title{
Intimacy Negotiated: The Management of Relationships and The Construction of Personal Communities in the Lives of Bisexual Women and Men.
}

\begin{abstract}
Bringing into dialogue conceptual literature on bisexuality, intimacy, and personal community, this paper illuminates the lived experiences of 80 bisexual women and men in the UK. The data was collected through questionnaire and individual interview. The paper discusses two empirical themes, beginning with the participants' narratives on their engagement with the dominant sexual and gender order - which hegemonizes 'monosexuality' and 'compulsory monogamy' - in their negotiation of relational intimacy. This is followed by an exploration of the features and functions of their personal communities, especially the significance of friendships. The paper argues that, despite the ambivalence and misperception surrounding bisexuality, the participants enacted creative agency in negotiating intimacy and social support in their everyday lives.
\end{abstract}

\section{Keywords}

Bisexual, intimacy, personal community, relationship, Christian

\section{Introduction}

Recent decades have seen the exciting proliferation of research on nonnormative sexualities, often incorporated into the category of 'LGBT' or 'queer'. Research of this kind plays a significant role in de-stigmatizing non-normative sexualities. Indeed, the production and circulation of insights about the lived experiences of non-normative sexual subjects has played a pivotal role in the 
establishment of their sexual or intimate citizenship in liberal democracies (e.g. Oleksy, 2009; Plummer, 2003, 2015; Richardson, 2000; Richardson and Munro, 2012). Nonetheless, a closer inspection would reveal that while lesbian and gay sexualities are increasingly socially-visible and legally-recognized, complemented by burgeoning public acceptance - and transgenderism is increasingly protected under gender equality legislation despite an uneven trajectory in terms of public acceptance (e.g. Davy, 2011; Hines, 2006, 2007a, 2007b; Hines and Sanger, 2010) - bisexuality as a lived sexuality and identity continues to be shrouded with ambivalence, misunderstanding, and prejudice (Flanders, 2016; Maliepaard, 2015). This scenario reflects not only personal attitudes towards bisexuality, but also the broader sexual and gender order, and the socio-political relations which contribute to 'bisexual erasure' (e.g. Rust, 2002; Yost and Thomas, 2012). In our view, there are two mutually-constitutive foundational - but often implicit - characteristics of this sexual and gender order which renders bisexuality problematic to many heterosexual and lesbian and gay people alike: 'monosexism'; and 'compulsory monogamy', which is closely associated with what Wilkinson (2013) calls 'compulsory coupledom'. Monosexism is a cultural ideology, a set of institutional practices, and individual attitude that demand a person's self-identification firmly and exclusively with one sexual identity. Monosexism operates on, and perpetuates, the hegemony of the hetero/homo dichotomy. Consequently, 'heterosexual' is a normative thus often unproblematized identity- and 'lesbian' and 'gay' are increasingly accepted identities - but this system of identification and stratification insists on an individual's attraction to either members of the same sex or opposite sex. This concretizes the exclusive occupation of one side of the hetero/homo and opposite-sex/same-sex taxonomy. 'Bisexuality', as it is popularly imagined (e.g. 'bisexuals must have a man 
and a woman simultaneously and in equal measure), disrupts this discursivelyproduced sexual and gender order that powerfully hegemonizes monosexuality, and, in turn, stigmatizes bisexuality. In the words of Rust, bisexuals are 'people whose common characteristic is their refusal to practice gendered exclusivity' (1995:241; See also Rust, 2000, 2002). Consequently, bisexuals are often misunderstood as promiscuous, closeted lesbians and gay men who are unwilling to forgo 'heterosexual privileges', and being on the transition to becoming 'out and proud' lesbians and gay men (Barker et al., 2012; Enstedt, 2015; Friedman et al., 2014; Kristal and Szymanski, 2006; Ochs, 2009; Ross, 2010).

The stigmatization of bisexuality underpinned by monosexism is inextricably linked to 'compulsory monogamy', which is the contested but powerfully hegemonic aspirational norm that governs the construction and management of couple relationships, regardless of the challenges in practising this norm in the highly sexualized everyday context. 'Compulsory monogamy' is powerful precisely because it is constructed as the normative cornerstone for couple relationships that supposedly reflects 'commitment', 'faithfulness' - and, most of all, 'love'. To many, it is a nonnegotiable sine qua non of romantic love: to love one's partner is to remain monogamous. We would argue that, in spite of the minority practice of polyamory and the sometimes idealized media representation of polyamorous relationships (Anapol, 1997, 2012; Barker, 2005; Barker and Langdridge, 2010a, 2010b; Sheff, 2005), 'compulsory monogamy' - closely associated with 'compulsory coupledom' (Wilkinson, 2013) as an aspirational narrative and a cultural norm - continues to hold sway as the defining characteristic of an 'authentic', 'committed' and 'fulfilling' couple relationship. It is precisely within this discursive context that bisexuals popularly but erroneously constructed as having to have members of the same and 
opposite sex simultaneously and in equal measure - encounter great difficulty in convincing people that monogamy is not antithetical to their sexuality and relationship aspiration, if so desired. Indeed, as Klesse argues, 'Non-monogamy is a troubling issue for many bisexuals, because dominant discourse constructs bisexuals as non-monogamous by necessity. The assumption that bisexuals have to be nonmonogamous or promiscuous flows from the traditional Western construction of sexuality in a dualistic scheme... A heightened sexuality, including non-monogamy or promiscuity, is a strong feature of biphobic discourses' (2007:78-79; His emphasis).

Therefore, despite the increasing legal recognition and social acceptance of sexual diversity and difference in liberal democracies, sexualities continue to be structured unequally; and we would argue that bisexuals often come off worst in this sexual stratification which is imbued with moralistic undertones. In this respect, we think it worthwhile to heed Gross' (2005) critique of the 'de-traditionalization of intimacy' thesis, so dominant in literature on intimate ties and practices in contemporary society, prioritizing 'plasticity' and 'liquidity' (e.g. Bauman, 2003; Giddens, 1992). Gross argues that 'regulative traditions' have indeed declined, so that heterosexual relationship/family has been de-centred, and same-sex relationship/family is increasingly included in the legal and social definition of fulfilling relationship/family. Nonetheless, he argues, 'meaning-constitutive traditions', namely, linguistic and cultural frameworks that prioritize, for instance, coupledom, romantic love, and monogamy, continue to inform individuals' sensemaking, and social relations. In line with this perspective, we would argue that the benefits of the de-traditionalization of intimacy are differentially experienced by different sexual communities. 
Against this backdrop, it is not surprising that bisexuality has attracted relatively limited attention within the corpus of research on non-normative sexualities. Our paper aims to fill this gap. In this paper, we explore the lived experiences of 80 bisexual women and men in the UK, specifically in their efforts to make sense of their intimate life within the linguistic and cultural frameworks that perpetuate monosexism and compulsory monogamy. We consider our bisexual participants 'intimate social agents', actively fostering multi-faceted intimate ties and personal communities within the everyday context, engaging with diverse tensions and opportunities.

Intimacy, as Jamieson has argued, 'refers to the quality of close connections between people and the process of building this quality.... [I]ntimate relationships are a type of personal relationships that are subjectively experienced and may also be socially recognized as close' (2011: para. 1.1). Intimacy, therefore, is about relatedness and closeness. To cultivate intimacy, individuals engage in 'practices of intimacy', which are 'practices which enable, generate and sustain a subjective sense of closeness and being attuned and special to each other' (Jamieson, 2011: para. 1.2; see also Jamieson, 1998). Crucially, such practices could be innovative, but also habitual, institutionalised, and culturally-scripted. Thus, they can subvert but also reinscribe dominant social norms, and inequalities (Gabb and Fink, 2015; Morgan, 2011). In the same vein, Layder also conceptualizes intimacy as being and doing: '[I]ntimacy cannot be properly understood without the due attention to the interpersonal dealings and transactions which are, in fact, its primary means of expression. In short, the way people "do", or "enact", intimacy is of paramount importance to understanding its nature' (2009: 2).

In the construction of intimacy, an individual establishes what Spencer and Pahl (2006) call a 'personal community'. Inhabiting this community are significant 
others to whom an individual is emotionally and instrumentally connected. Put differently, these are 'intimate others' with whom an individual engages in diverse practices of intimacy. These at times hidden solidarities and ties play a pivotal role in the individual's navigation of a risk-laden and contingent contemporary terrain of social relations. Crucially, membership to this community is not rigid, prioritizing either blood family members or friends. Rather, there is a high degree of 'suffusion' between the traditional demarcation of family and friends. The key here is the depth of intimacy and connection within the personal community, not the status of the significant others within it (see also Pahl and Spencer, 2004).

The primary aim of this paper is to bring into dialogue literature on bisexuality, intimacy, and personal community, illuminated through the lived experiences of bisexual women and men in the UK, who also profess a Christian faith, albeit with different levels of engagement. ${ }^{1}$ The paper will highlight two empirical themes, beginning with the participants' narratives on their engagement with the broader sexual and gender order in their negotiation of relational intimacy. This is followed by an exploration of the features and functions their personal communities, especially the significance of friendships. Altogether, these themes illuminate how a grossly-understudied community of non-normative sexual subjects make sense of their intimate worlds by engaging with the enabling and constraining potentials of the sexual and gender order.

\section{Methodological account}

This paper presents data collected from a British project which explored the construction and negotiation of identity in the lives of 80 bisexual women and men. As mentioned above, the participants also defined themselves as 'Christian', with 
diverse beliefs and practices. Appreciating the lack of formal support networks specifically for bisexual Christians and the difficulties in accessing this partiallyhidden population, diverse sampling methods were employed. These methods included: advertisement in print magazines and support group bulletins (e.g. Gay Times, Bi Community News, and the Metropolitan Community Church newsletters), snowball sampling, and the first author's personal networks.

Aiming to collect qualitative and quantitative data, two main research methods were utilised: questionnaire and individual semi-structured interview. The questionnaire contained 44 closed and open-ended questions, organized into six sections: (i) demographics; (ii) relationships; (iii) sexuality; (iv) religious faith and practice; (v) support networks; and (vi) life as a bisexual Christian. Each participant who completed the questionnaire was invited to be interviewed. Amongst those who responded positively, twenty were selected based on the principle of participant variability (e.g. geographical location, gender, conception of bisexuality). The completed questionnaires were used as the basis of the interviews. As previously noted (Toft, 2012a), the interviews were flexible and offered the participants a loose structure to explore their reflections on the questionnaire themes. The interviews - all digitally-recorded - took about one-and-a-half hours each, and were held mainly in participants' homes. The questionnaire data was analyzsed using SPSS, and the interview data was subjected to a thematic analysis (e.g. Esterberg, 2002).

The main sample consists of $42(52.5 \%)$ women and $38(47.5 \%)$ men, ${ }^{2}$ with an age range of 18 to $72($ mean $=29)$. The vast majority $(78 ; 97.5 \%)$ self-defined as 'white British'. Seventeen participants (21.8\%) were single; and 52 (66.7\%) were in couple relationships (33 cross-sex and 19 same-sex). Furthermore, nine participants $(11.5 \%)$ were in relationships with at least three partners, with a mixture of cross-sex 
or same-sex partners. ${ }^{3}$ The duration of the relationships ranged from 1 month to 32 years.

\section{Contesting monosexism and compulsory monogamy in intimate lives}

This section begins with the participants' self-definitions of bisexuality, highlighting the cultural currents of monosexism that they had to navigate. We then turn our attention to illuminating how they manage intimacy within relational contexts.

\section{Personal understandings of bisexuality}

In line with the literature that demonstrates bisexuals' diverse constructions of their identity, many of the participants rejected gender exclusivity that underpins monosexism as the basis for their sexual attraction and emotional attachment. This is cogently expressed by Stuart, a 25-year student from the North of England. Stuart was in a month-long non-cohabiting cross-sex relationship, and his girlfriend also selfidentified as bisexual:

I am bisexual, which means to me that gender is not a barrier to physical attraction, having sexual relations, and emotional attachment. I do not possess a finite amount of attraction that must be carefully portioned out to each gender in a calculated proportion. The idea of being more attracted to one gender or another doesn't really make sense to me in my experience. I am bisexual. Gender is not a barrier to sexual attraction for me as it is for other people. I would be happy to fall in love, marry, and be monogamous for life with someone of either gender. 
Stuart's understanding of his sexuality de-emphasizes the gendered nature of sexual attraction and emotional attachment; and in turn amplifies the significance of the intimate object's qualities and characteristics. This is also expressed by Elanor, a 24year-old Londoner who had been in a relationship with a man for four years. She considered the relationship to be long-term and that they would eventually live together after they had completed their university studies:

I'm trying to describe [my sexuality] to the best of my ability, [but] it's very difficult. I am attracted to people and to their minds and how we relate to each other. That is what bisexuality is to me: relating to other people. The sex of the person is not a part of it and shouldn't really be discussed. If we relate to each other in a special way, then something may come out of it.

The above narratives' emphasis on gender-transcending characteristics - reflecting the popular trope 'it is the person that counts'- fundamentally challenges the discursively-produced association between sexual attraction and gendered body, which hegemonizes heterosexuality - and increasingly accepting of homosexuality but continues to invisibilize and marginalize bisexuality.

\section{Managing intimacy in relational contexts}

The majority of the participants in the main sample $(52 ; 66.7 \%)$ described themselves as a being in a couple relationship. Of these, about one-third $(17 ; 32.7 \%)$ had partners who self-defined as 'bisexual'. In other words, about two-thirds of them were in couple relationships where the partners defined themselves as either 'heterosexual', 
'lesbian' or 'gay', which means that prejudice and misunderstanding about bisexuality as we have discussed above might inform the management of such relationships.

Kimberly, a 29 year old from the Northwest of England, was single, but had been in various monogamous couple relationships, with either a woman or a man at a particular time. She particularly highlighted how difficult it was for her female as well as male partners to understand her sexuality particularly in relation to issues of monogamy and 'faithfulness'.

I got together with my last [male] partner, who was at [university] doing the 4th year of his physics Master's degree, and he found my bisexuality difficult in the same way that [a previous female partner] did. He wanted me to be heterosexual. He said, 'Now you are with me, you are heterosexual'. And I said, 'I'm not actually. I'm still bisexual. Although I'm with you exclusively, it doesn't make me heterosexual; although it's immaterial really'.

Kimberly's narrative clearly demonstrates the challenges many bisexuals must negotiate in their intimate relationships with non-bisexual partners who have often internalized discursively constructed prejudices about the nature of bisexuality, which question bisexuals' commitment to a monogamous relationship. Therefore, it is not surprising that some participants preferred to form intimate relationships with those who also self-defined as bisexual. Stuart, whom we have introduced above, had previously been in a relationship with a heterosexual woman, but was keen to point out that he found it easier to be involved with someone who identified as queer or bisexual: 
In my experience, it is easier for me to be in a relationship with a queer person - gay/bi man or bi woman - because there is more in common to base the relationship on. Although in a previous relationship with a straight woman I was open about my bisexuality, it felt like it was an issue and a place of contention in some ways. It feels more comfortable to me now to be in a relationship with a bi woman.

Contrary to popular misunderstandings of bisexuality, the participants also argued that they did not need to affirm their bisexual identity by being in relationships with members of both sexes concurrently. In fact, many of them preferred to be in a relationship with one partner at a time, but their choice of partner transcended gender binary and specificity. In such cases, their sexual identity was therefore predicated on their sexual history which reflected their involvement with members of both sexes. This is clearly articulated by Samantha, a 19-year old from the Northwest of England. Samantha was single, having recently ended a relationship with a man; and she imagined whether the relationship would have been different if her partner were a woman:

I cannot ever imagine being with two [partners] because when I am with my partner it is because I am attracted to her, what she looks like and how she is with me... and with others I suppose. It's not like I am ignoring this stuff. It is just I will only be with that person.

Samantha's reflection is echoed by a number of participants, such as Jim, a 26-yearold from the Midlands of England, who had been in a cross-sex couple relationship 
for two years. In his sexual journey, he had been in more relationships with women than men but had always practised monogamy in all those relationships. He stated:

When I'm involved with a girlfriend I am not thinking about what I'm missing from male company... It's not like I cannot be aroused if I don't have both.

Klesse's (2007) important work on polyamorous relationships, for example, highlights the potential link between maintaining a bisexual identity and having concurrent relationships with members of different sexes. As indicated above, nine participants were in polyamorous relationships, some with members of both sexes. A good example of this relationship arrangement is Daniel, a retired man from the Southwest of England. Daniel was part of a group of six male partners who socialized and had sex, with a variety of permutations.

I never had anyone living in with me [since his wife had died about five years ago]. The first two guys I met, they discouraged me about thinking about a monogamous relationship. They thought it was better not to limit contacts, as [such relationships] tend to break down. I meet them separately... When I considered my family situation and social situation and church in [his town], it would cause considerable discomfort if someone lived in, unless I uppedsticks and left, which I didn't want to do. So I came to the view that it would be quite nice to have several guys, not a specific number, but a group of friends with whom I could spend a day or a night... And sometimes we do meet up together and have a meal. Not all of us, but three or four. We are all known to each other and ask after each other... I began to think about myself 
as bisexual because my life history suggests I probably am. I am interested to find that a lot of men have similar thoughts and actions. Several of the men I know are married; their wives have died and are following a similar path to myself. I think bisexual is the best word we have got to describe a guy who is equally happy with either relationship, sometimes simultaneously, but in my case, successively.

Daniel's experience clearly illustrates the various constraints and opportunities with which he engaged in order to live out his bisexual identity in meaningful ways. While his polyamorous arrangement with the other men undoubtedly required careful planning, it had provided a significant context for intimacy-making and supportgeneration in diverse ways. In this section, we have presented narratives that demonstrate the perpetual and dominant misunderstandings of bisexuality that participants had had to negotiate in their everyday life. This proved to be a significant issue in not only their self-understandings, but also in managing intimate relationships. This is precisely the focus of the next section, in which we shall turn the spotlight on their practices of intimacy within the broader social context, by engaging with the enabling and constraining potentials of the sexual and gender order.

\section{Constructing personal communities}

Personal communities of different shapes and forms play a significant role in the construction and practices of intimacy. In this section, we shall examine three specific contexts - namely, support groups, religious communities, and friendships - within which the participants constructed and negotiated intimacy by way of developing social capital for the everyday living-out of their bisexual identities. 


\section{Bisexual-specific support groups}

Bisexual-specific support groups are rare. Therefore, bisexuals have to settle for support groups conventionally labelled as lesbian, gay and bisexual, which in reality prioritize the interests and needs of gay men, and to a lesser extent, lesbians. Only 26 $(32.5 \%)$ of the sample had ever attended bisexual-specific support groups. These participants cited two key reasons for attendance: to keep abreast with current news and events, and to be in a safe environment where their sexuality is understood and accepted. These reasons are consistent with well-established research findings that illustrate the importance of support groups for sexual minorities more generally in the development of a sense of belonging and solidarity, effecting a positive impact on the management of their minority identities in everyday life (e.g. Browne et al., 2009; Paternotte and Tremblay, 2015).

Nonetheless, two-thirds of the sample expressed ambivalence about being involved in such groups. For example, $49(62.8 \%)$ of the sample said that they did not have the need to use support groups to socialize; and 44 (56.4\%) were apathetic about using support groups to keep up with news and events. In addition, a number of the participants found it difficult to attend these support groups because of the tension they experienced between their sexual and religious identities. Phillip, a 55-year-old Methodist from the Southeast of England, had been married for 32 years. He noted that he felt sexually fulfilled. However, during his interview he also suggested that he had a 'gay side' which had never subsided and that he considered himself bisexual. This was based upon his sexual involvement with men prior to his marriage. $\mathrm{He}$ talked about how his religious identity posed some difficulty to his desire to express his sexuality: 
I tried tentatively to go to one or two [support groups]. There was one in North London. If you do have religious beliefs and they are important to you it's different and confused because there are conflicts. I really don't find support groups help with that. To be a Christian is a problem in many circles, or perceived to be a problem. To be gay is something else. To be married for a large part of my life and to have two children, is a complication that I can't find a very good answer to.

Phillip's non-involvement in support groups seems to be underpinned by his recognition that they would provide a safe environment for him to address the incompatibility of his sexuality and religious faith. But that was precisely the scenario that he wanted to avoid, being cognisant of the personal costs. Phillip's experience is often reflected in the proliferating research literature on the tension experienced by religious lesbian, gay, and bisexual people in their attempts to manage their sexual and religious identities in everyday contexts (e.g. Toft, 2012a, 2012b, 2014; Taylor, 2016; Yip, 2010). Jim, a 26-year-old from the Midlands, also took a highly personalized approach to the resolution of his sexuality and religious faith. To him, such efforts were private matters that did not warrant a public airing. This is an interesting rationalization, highlighting the fact the capitalization of the social capital offered by support groups does require the individual to engage publicly with such spaces, which they may not be comfortable to do. Jim argued:

I've got friends who swear by talking to people and going to all sorts of group activities and expedition and so forth. But it's such a personal thing that when 
it [his bisexuality] is combined with my religious beliefs it's kind of messy, and I wanted to work through it by myself. I did talk to partners about things though because that's just what you do, isn't it?

Some participants, such as Samantha, a 19-year-old from the Northwest of England, also argued that support groups tended to operate on the principle of 'helping by fixing', rather than giving space and time to individuals to find their own ways to carve out their own journeys of sexuality and religious faith:

I don't need support, I really don't. I go out and meet people and I socialise with Christians through my family but that's just to meet people. No-one needs to fix me.

In the same vein, Jim, whom we have introduced above, asserted:

A support group is just so negative, like I can't deal with things myself...Y Your religion and your sexuality are at your very core, aren't they? It's what makes you what you are.

Narratives articulated by Samantha and Jim are telling, because they demonstrate how support groups - and the positive impacts they are supposed to generate - are in reality perceived in a diverse rather than a monolithic fashion. Participants such as they viewed support groups as putting them in a position of needing support and 'to be fixed'. Therefore, they challenged the conventional view that people would access support groups because of such groups' inherent positive values. This illustrates that 
the management strategies of sexuality and spirituality are diverse, with multiple outcomes (e.g. Browne et al., 2010; Hunt and Yip, 2012; Nynäs and Yip, 2012; Smith et al., 2016; Taylor and Snowdon, 2014; Yip, 2015; Yip and Page, 2013).

\section{Religious communities}

Only a small proportion of the sample $(14: 17.9 \%)$ stated that their involvement with the religious communities gave them adequate support as bisexual Christians. This is not surprising, given research findings that continue to show the heteronormative nature of religious spaces (e.g. Toft, 2012b, 2014; Browne et al., 2010; Yip and Page, 2013). However, the participants highlighted the fact that religious communities did need to be inclusive and welcoming to all. Cynthia, a 43-year-old from the Southwest of England who had been in a same-sex relationship for just over a year, and was planning for a civil partnership. She discussed the need for the church to support everyone:

We need a church that is wholly inclusive, that will accept the single mums, the travellers down the road. You don't have to wear your pearls, you come as your whole sexual being and spiritual being to worship God, and gain support from within and teach from within as well. We have people who don't know anything at all about the sex issues or the diverse issues that are faced by bisexuals so we teach about this rather than having an exclusive group for bisexuals that does not educate...That would be my ideal church.

Even in religious communities that were known for its sexually-inclusive ethos, bisexuals continued to feel excluded. For example, at the Metropolitan Community 
Church (MCC), known for its open-door policy to the socially-marginalized, Judith, a 38-year- old single woman from the London, felt that she was not as accepted by the community compared to her lesbian and gay counterparts:

I recently attended the MCC - a gay-led congregation. They were totally geared to lesbians and gay men only, and they were also very family orientated. If you had one [partner] of the opposite sex [thus assumed to be heterosexual], you were pretty much ignored and dismissed.

\section{Informal solidarities: friendships}

Thus far, the second empirical theme has shown that the vast majority of the participants did not consider bisexual-specific support groups and the religious communities as significant components of their personal communities. In other words, they were not significant intimate others with whom the participants related and from whom high level of intimacy was cultivated. Rather, many participants prioritized intimate others from friendship networks. A good example of this is Kimberly, a 29year-old from the Northwest of England. She did not like support groups, but relished the life-affirming and enriching intimacy found in informal friendship networks:

I don't think I should have to go to some weird group full of people who are different... And then I met up with a woman who had been through similar life experiences to me, and she introduced me to [other] people with similar life-stories to us... and I feel like I've found a real church, somewhere where I recognise the God people are talking about, and there's no official church setting, there's no communion, no of the usual accompaniments to 
Christianity. It's more about having a meal together or just being at the end of the phone. Or sometimes we might organise a fun day where we all go to the beach. Sometimes, people will just sing songs that come into their head, Christian songs.

Kimberly's narrative illustrates a crucial point about the glue that binds intimate agents of a personal community: story-telling, based on individual lived experiences. The telling of such stories - however informal, gradual, and tentative - reveals the experiential connections between the intimate agents, which in turn constitutes the emotional foundation on which such intimacy is flourishes (Plummer, 1995, 2015). In the same vein, Adam, a 63-year-old man from the Southeast of England, also talked about the importance of informal personal community. Adam was a divorcee and had been in a three-and-a-half-year same-sex relationship. He socialised with his vicar and used this opportunity to discuss personal issues and to relax:

The vicar who was there [at his local church] when I went there, he and I became close friends, I toyed with coming out to him time and time again. We would go once a month for a couple of pints in the pub, and it was two or three hours of solid nattering. Initially it was a chance for me to unwind but after a while he said it was a chance for him to let his hair down as well, with someone who he could natter to easily. And because we got on so well, a bit of me was dying to be more honest with him, and another part of me thought, do I need that sort of risk because we had talked about gays occasionally and he wasn't totally anti, but I got the impression that he was towing the semichurch line if you like. 
The practice of intimacy that Adam and his vicar were involved in generated an incrementally safe space for Adam to want to disclose his sexuality to the vicar. His experience attests to the incremental impacts practice of intimacy could have on personal relationships and friendships, facilitating the cultivation of trust and connectedness, and in turn, greater self-disclosure (Helm, 2010; Spencer and Pahl, 2006; Vernon, 2010). This kind of informal, even hidden, solidarities are crucial to the construction of the participant's personal communities (Spencer and Pahl, 2006). Their construction and cultivation is often gradual and incremental, as highlighted by Phillip, a 55-year-old from the Southeast of England:

I think people who are alike tend to group together, that's how life is. But that doesn't always happen in real life. The groups we are part of, with our similarities, sexuality, religion and so forth, we don't come together naturally, and in our normal life we aren't like that. You form your own support networks.

Similarly, Adam, whom we have introduced, also talked about the value of friendship networks, of which he was a part:

There's a little group of us that meet in [city] once a month. We have tea and biscuits and for a couple of hours talk about anything... I met one of the guys through Gaydar and he knew some of the others and that was that... We've been going for two or three years now... We're all [aged] 40 plus. It's like 
another church.... it's the social side of another small church if you like. What constitutes a church? The eight of us together is a church, totally unofficial.

The unofficial and informal dimension that Adam alluded to was highly significant to the practices of intimacy that built, incrementally, the cornerstone of the personal communities. If support groups were deemed too formal - and religious community too exclusive, heteronormative, and lesbian-and-gay-prioritizing - then it was precisely the informal and fluid characteristics of friendship networks that sowed the seed of intimacy, trust, and connection.

\section{Concluding Remarks}

Drawing from conceptual literature on bisexuality, intimacy, and personal community, this paper has illuminated the lived experiences of 80 bisexual women and men, with special reference to two themes. First, we have demonstrated that the participants' self-definitions of their sexuality were often at odds with the ideology of 'monosexism' that hegemonizes the hetero/homo binary, and gendered nature of sexual and emotional attraction. This is compounded by 'compulsory monogamy', the dominant aspirational norm that underpins the popular construction of 'committed' and 'faithful' intimate (couple) relationships, which coalesces with the misunderstanding that bisexuals are incapable of such an aspiration (if so desired). These two inextricably-linked ideologies position bisexuals in a challenging everyday situation which they have to navigate in the management of their intimate life. In the second theme we have explored the features and functions the participants' personal communities. We conclude that, compared to bisexual-specific support groups and religious community, friendship networks were substantially more significant in the 
everyday living-out of their bisexual identities. In other words, compared to more formal affiliations and spaces, friendships, as informal solidarities and ties, play a much more meaningful role in the participants' construction of intimate lives within the context of the aforementioned rigid sexual and gender order.

Taken together, the two empirical themes this paper has covered also demonstrate that bisexual's lived experiences make a significant contribution to the problematization of dominant gender, sexual, and relationship norms. Importantly, Udis-Kessler argues that, 'Experiences of bisexuals offer a model for life outside the boundaries of destructive hierarchical dualisms' (2000: 15). In other words, the lived experiences of bisexuals compel us to problematize, de-stabilize, and re-think the dualistic and hierarchical conception of human sexuality and gender, and indeed human life itself. Such dualisms - e.g. white/black, men/women, heterosexual/homosexual - which assume the superiority of the former, and the inferiority of the latter have exacted heavy social, political, and personal costs on human life throughout history. In this respect, as we have stated in Endnote 2, we do acknowledge that the fact that none of our participants self-identified as 'trans' and none had had a relationship with a trans person, by sheer coincidence rather than by research design, has limited our ability to critique 'gender dualism' empirically and conceptually within the remit of this paper. Nonetheless, looking at this limitation positively, we would like to argue that this signposts a research avenue to pursue in the future.

In terms of intimate relationships, Anderlini-D’Onofrio rightly argues that, 'Bisexuals can definitely be as monogamous as anybody else, but the good news is that they don't have to in order to be honest with their partners and create responsible love relationships considerate of each participant's feelings' (2004: 3). Following 
Anderlini-D'Onofrio (2004), we would assert that, notwithstanding the challenges in everyday practice, bisexual identity can be an impetus for reflexive and negotiated intimacy where intimate partners engage in an honest assessment of dominant cultural norms about sexuality and intimacy. Such negotiation constitutes a more critical, reflexive - thus more responsible and responsive - way of practising intimacy in diverse ways. Therefore, bisexuality disrupts the dominant sexual and gender order that limits human potential for intimacy-making. On the specific issue of monogamy, not all bisexuals, for diverse reasons, desire a non-monogamous relationship of course. But we would argue that the uniqueness of their sexuality places bisexuals in a potentially fruitful position to critique monogamy, more so than heterosexual, lesbian and gay people (e.g. Anapol, 2012; Sheff, 2014). 'Queering' efforts such as this, in essence, would approximate the ideal of 'cosmopolitan sexualities' that acknowledges the variety, contingency, and plurality of human sexualities (Plummer, 2015).

\section{Notes}

1. The remit of this paper means that the religious dimension of their lives will not be foregrounded, unless when it is specifically related to the issues discussed. For publications that prioritize the religious dimension, see Toft (2009a, 2009b, 2012b, 2014)

2. Although the study was open to participants of diverse gender identities, none of the participants self-identified as 'trans', and none had had a relationship with a trans person. Thus, we acknowledge that our study, by sheer coincidence rather than by design, reflects such a sample specificity and methodological limitation.

3. Two participants did not answer the questions about relationship status. 


\section{Acknowledgment}

The authors would like to thank the participants for telling their stories and their generosity with time. We are also grateful to the reviewers for their helpful and supportive feedback.

\section{Funding}

The research was funded by the Economic and Social Research Council (Award No: PTA-030-2006-00245).

\section{References}

Anapol D (1997) Polyamory: The New Love Without Limits. London: Intinet Resource Center.

Anapol D (2012) Polyamory in the $21^{\text {st }}$ Century. London: Rowman and Littlefield. Anderlini-D'Onofrio S (2004) Plural Loves. New York: Harrington Park Press.

Barker M (2005) This is my partner, and this is my..... partner's partner: Constructing a polyamorous identity in a monogamous world. Journal of Constructivist Psychology 18(1): 75-88.

Barker M and Langdridge D (2010a) Understanding Non-monogamies. New York: NY: Routledge.

Barker M and Langdridge D (2010b) Whatever happened to non-monogamies? Critical reflections on recent research and theory. Sexualities 13(6): 748-772.

Barker M, Richards C, Jones R, Bowes-Cotton H and Plowman T, with Yockney J and Morgan M (2012) The Bisexual Report: Bisexual Inclusion in LGBT Equality and Diversity. Milton Keynes: The Open University. Available at: 
pdf (accessed 30 September 2015)

Bauman Z (2003) Liquid Love. Cambridge: Polity Press.

Browne K, Munt SR and Yip AKT (2010) Queer Spiritual Spaces: Sexuality and Scared Places. Farnham: Ashgate.

Davy Z (2011) Recognising Transsexuals: Personal, Political and Medicolegal Embodiment. Farnham: Ashgate.

Enstedt D (2015) Blessing same-sex unions and the invention of a 'genuine homosexuality' in the Church of Sweden. Sexualities 18(5/6): 564-592.

Esterberg KG (2002) Qualitative Methods in Social Research. Boston, MA: McGrawHill.

Flanders, CE (2016) Bisexuality, social identity, and well-being: An exploratory study. Sexualities 19 (5/6): 497-516.

Friedman MR, Dodge B, Schick V, Herbenick D, Hubach Randolph D, Bowling J, Goncalves G, Krier S, and Reece M (2014) From bias to bisexual health disparities: Attitudes toward bisexual men and women in the United States. LGBT Health 1(4): 309-318.

Gabb J and Fink J (2015) Couple Relationships in the $21^{\text {st }}$ Century. Basingstoke: Palgrave Macmillan.

Giddens A (1992) Transformation of Intimacy. Cambridge: Polity Press.

Gross N (2005) The detraditionalization of intimacy reconsidered. Sociological Theory 2(3): 286-311.

Helm, BW (2010) Love, Friendship and the Self. Oxford: Oxford University Press. Hines S (2006) Intimate transitions: Transgender practices of partnering and parenting. Sociology 40(2): 353-371. 
Hines S (2007a) TransForming Gender: Transgender Practices of Identity, Intimacy and Care. Bristol: Policy Press.

Hines S. (2007b) (Trans)forming gender: Social change and transgender citizenship. Sociological Research Online 12(1).

http://www.socresonline.org.uk/12/1/hines.html (accessed 15 September 2015)

Hines S and Sanger T (2010) Transgender Identities: Towards a Social Analysis of Gender Diversity. London: Routledge.

Hunt S and Yip AKT (2012) The Ashgate Research Companion to Contemporary Religion and Sexuality. Farnham: Ashgate.

Jamieson L (1998) Intimacy: Personal Relationships in Modern Societies. Cambridge: Polity Press.

Jamieson L (2011) Intimacy as a concept: Explaining social change in the context of globalisation or another form of ethnocentricism? Sociological Research Online 16(4). http://www.socresonline.org.uk/16/4/15.html (accessed 3 September 2015)

Kristal N and Szymanski M (2006) The Bisexual's Guide to the Universe: Quips, Tips, and Lists for Those Who Go Both Ways. New York, NY: Alyson Books.

Klesse C (2007) The Spectre of Promiscuity: Gay Male and Bisexual Nonmonogamies and Polyamories. Aldershot: Ashgate.

Layder D (2009) Intimacy and Power: The Dynamics of Personal Relationships in Modern Society. Basingstoke: Palgrave Macmillan.

Maliepaard E (2015). Bisexual citizenship in the Netherlands: On homo-emancipation and bisexual representations in national emancipation policies. Sexualities 18(4): 377-393

Morgan DHJ (2011) Rethinking Family Practices. Basingstoke: Palgrave Macmillan. 
Nynäs P and Yip AKT (2012) Religion, Gender and Sexuality in Everyday Life.

Farnham: Ashgate.

Ochs R (2009) Getting Bi: Voices of Bisexuals around the World. Boston, MA:

Bisexual Resource Centre.

Oleksy EH (2009) Intimate Citizenships: Gender, Sexualities, Politics. London:

Routledge.

Pahl R and Spencer L (2004) Personal communities: Not simply families of 'fate' or 'choice'. Current Sociology 52(2): 199- 221.

Paternotte D and Tremblay M (2015) The Ashgate Companion to Lesbian and Gay Activism. Farnham: Ashgate.

Plummer K (1995) Telling Sexual Stories: Power, Change and Social Worlds. London: Routledge.

Plummer K (2003) Intimate Citizenship: Private Decisions and Public Dialogues.

Seattle, WA: University of Washington Press.

Plummer K (2015) Cosmopolitan Sexualities: Hope and the Humanist Imagination. Cambridge: Polity Press.

Richardson D (2000) Constructing sexual citizenship: Theorizing sexual rights. Critical Social Policy 20(1): 105-135.

Richardson D and Munro S (2012) Sexuality, Equality and Diversity. Basingstoke: Palgrave MacMillan.

Ross LE, Dobinson C and Eady A (2010) Perceived determinants of mental health for bisexual people: A qualitative examination. American Journal of Public Health 100(3): 496-502.

Rust PC (1995). Bisexuality and the Challenge to Lesbian Politics: Sex, Loyalty and Revolution. New York University Press 
Rust PC (2000) Bisexuality in the United States: A Social Science Reader. New York: Columbian University Press.

Rust PC (2002) Bisexuality: The state of the union. Annual Review of Sex Research 13(1): 180-240.

Sheff E (2005) Polyamorous women, sexual subjectivity, and power. Journal of Contemporary Ethnography 34(3): 251-283.

Sheff E (2014) The Polyamorists Next Door: Inside Multiple-Partner Relationships and Families. Lanham: MD: Rowman \& Littlefield.

Smith S, Munt SR and Yip AKT (2016) Cosmopolitan Dharma: Race, Sexualit, and Gender in British Buddhism. Leiden: Brill.

Spencer L and Pahl R (2006) Rethinking Friendship: Hidden Solidarities. Princeton, NJ: Princeton University Press.

Taylor Y (2016) Making Space for Queer-Identifying Religious Youth. Basingstoke: Palgrave Macmillan.

Taylor Y and Snowdon R (2014) Queering Religion, Religious Queers. London, Routledge.

Toft A (2009a) Negotiating Identity: Life Narratives of Bisexual Christians'. In: Robinson, D. \& Fisher, $\mathrm{P}$ et al (eds) Narrative, Memory and Identities. Huddersfield: University of Huddersfield, pp. 127-135.

Toft A (2009b) Bisexual Christians: The Life-Stories of a Marginalised Community. In: Hunt, S (ed) Contemporary Christianity and LGBT Sexualities. Aldershot: Ashgate, pp. 67- 85 .

Toft A (2012a) Researching bisexuality and Christianity: Locating a hidden population and the implementation of research methods. In: Phellas CN (ed) Researching Non-heterosexual Sexualities. Aldershot: Ashgate, pp. 41-56. 
Toft A (2012b) Bisexuality and Christianity: Negotiating Disparate Identities. In: Hunt S \& Yip AKT (eds) The Ashgate Research Companion to Sexuality and Religion. Aldershot: Ashgate, pp. 189-210.

Toft A (2014) Re-imagining bisexuality and Christianity: The negotiation of Christianity in the lives of bisexual women and men. Sexualities 17(5-6): 546564.

Udis-Kessler A (2000) The holy leper and the bisexual Christian. In: Kolodny D and Hunt M (eds) Blessed Bi Spirit: Bisexual People of Faith. New York: Continuum, pp. 11-16.

Vernon M (2010) The Meaning of Friendship. Basingstoke: Palgrave Macmillan. Wilkinson E (2013) Learning to love again: 'Broken families', citizenship and the state promotion of coupledom. Geoforum 49: 206-213.

Yip AKT (2010) Coming home from the wilderness: An overview of recent scholarly research on LGBTQI religiosity/spirituality. In Browne K, Munt SR and Yip AKT (eds.) Queer Spiritual Spaces: Sexuality and Sacred Places. Farnham: Ashgate, pp. 35-50.

Yip AKT (2015) When religion meets sexuality: Two tales of intersection. In: Dickey Young P, Shipley H and Trothen T (eds.) Religion and Sexuality: Diversity and the Limits of Tolerance. Vancouver: University of British Columbia Press, pp. 119-140.

Yip AKT and Page S (2013) Religious and Sexual Identities: A Multi-faith Exploration of Young Adults. Farnham: Ashgate.

Yost MR and Thomas GD (2012) Gender and binegativity: Men's and women's attitudes toward male and female bisexuals. Archives of Sexual Behavior 41(3): 691-702. 